\title{
FILOSOFÍA Y TEOLOGÍA EN EL S. XIII. UN CASO DE DELIMITACIÓN: LA 'CREATIO EX NIHILO' COMO 'CREDIBILIA' SEGÚN GROSSETESTE
}

\author{
Celina A. Lértora Mendoza \\ CONICET-Buenos Aires
}

\section{RESUMEN}

Uno de los problemas más interesantes discutidos en el siglo xiii versaba sobte la delimitación epistemológica entre filosofía y teología. Destacamos a Roberto Grosseteste por ser uno de los últimos exponentes de la tradición monástica, al tiempo que plantea nuevos problemas. Su intuición acerca de la inconmensurabilidad entre el lenguaje filosófico y el teológico le llevó a postular los «credibilia» como una clace de proposiciones teológicas, por oposición a los «scibilia» (demostrables) de la filosofía (o ciencia, en sentido peripatético).

Palabras clave: Roberto Grosseteste, filosofía medieval, teología medieval, proposición demostrable, proposición probable.

\begin{abstract}
The epistemological delimitation between philosophy and theology was one of the most interesting problems discussed in the Thirteenth Century. Discussions around the object of theology prove this. Among the authors in the first half of the two hundreds, Roberto Grosseteste shows a particular interest because he represents one of the last exponents of the monastic tradition, but already open to new problems. His -well founded-intuition of the incommensability of the philosophical and theological language takes him to postulate the "credibilia" as a proper kind of theological propositions, in opposition with the scibilia (demonstrables) of philosophy (or science, in the peripathetic sense). The first credibilia enunciated in the text revealed is the creation of nothingness, the importance of which lies in its (al least apparent) contradiction with the Aristotelian physics a model of rational knowledge. Grosseteste assumes in this case (and for all the credibilia) the need of a rational process demonstrating its «credibility» defined in terms of «probability».
\end{abstract}

Key words: Robert Grosseteste, Medieval Philosophy, Medieval Theology, Demonstrable proposition, Probable proposition.

\section{PRESENTACIÓN}

La constitución sistemática de la Fỉosofía y la Teología como disciplinas epistemológicamente independientes es un proceso que se cumple a mediados del s. XIII, con la aparición de las grandes Summas teológicas que estructuran la disciplina deslindándola de la filosofía y constituyendo a ésta, definitivamente, en un saber exclusivamente racional natural. Este proceso fue precedido por una larga tradición teológica no menos rica, pero orientada por otros parámetros metodológicos en los cuales el deslinde era menos claro. Este género filosófico-teológico, tan dilatado temporalmente (ss. VIII-XII) como variopinto en sus manifestaciones 
(abarca todo lo que no pertence al género estrictamente patrístico ni al escolástico) que ha dado en llamarse «teología monástica» y que algunos, como R. Gregoire, denominan «teología sapiencial»' ha sido la caldera en que maduraron las grandes ideas de la teología escolástica. Problemas que los escolásticos tratan con pasmosa seguridad, como el objeto de la teología, los presupuestos racionales de la fe, el carácter del lenguaje revelado, etc. fueron objeto de dudas y arduas cavilaciones, en las que la filosofía no estuvo ausente. Y si los escolásticos de mediados del XIII pudieron ofrecer soluciones convincentes y bastate satisfactorias (como que duraron por lo menos cuatro siglos sin mella) fue porque recibieron un acervo ya suficientemente elaborado como para ser estructurado y reelaborado con facilidad de acuerdo a las nuevas categorías teológicas.

El problema de las relaciones entre fe y razón fue uno de los temas acuciantes del pensamiento medieval y es también un parteaguas en el proceso de deslinde metodológico entre filosofía y teología en el s. XIII. Cuando - desde fines del s. XI- la reintroducción de textos peripatéticos puso en confronte el sistema sapiencial con el aristotélico, la cuestión tomó un giro que la aproxima a las soluciones metodológicas de la escolástica.

Los últimos representantes de esta tradición monacal o sapiencial, los que todavía en el s. XIII intentaban la elaboración de una teología basada en la «lectio divina», son quizá los más interesantes exponentes del valor teológico y filosófico del abordaje temático. Roberto Grosseteste (1175?-1253), lector de los Franciscanos, Maestro de Oxford y Obispo de Lincoln, se sitúa en la línea que comentamos, sobre todo por su Hexaemeron, que puede considerarse una síntesis última de la teología del monacato. Pero no sólo recoge allí una notable selección de ideas patrísticas, sino que intenta una solución sistemática de los problemas surgidos al hilo del comentario de los primeros versículos del Génesis. Es notable su texto sobre el objeto de la teología ${ }^{2}$ cuyas reminiscencias hallaremos más tarde en el escolástico Duns Scoto. A continuación de esa exposición, menciona Grosseteste algunas cuestiones que hoy llamaríamos «limítrofes» o "puentes» entre filosofía y teología y que los manuales modernos abordarán en los capítulos iniciales, a modo de fundamentos racionales (racionalizables) de la fe. El dogma de la creación de la nada ha sido y es uno de los «puentes» más significativos en el esfuerzo constante por conectar y a la vez deslindar la fe y la razón y con ellas la teología y la filosofía. Hubo muchos modos de intentarlo. Grosseteste, siguiendo una tradición que luego de él también tuvo

1 Cf. «Théologie monastique», Lettre Ligure, n. 192, 1978: 25-30. Este autor considera que es la teología por excelencia, prolongación de la lectio divina y fruto de una experiencia interior.

2 Obra compuesta aproximadamente entre 1230 y 1235 , es decir, antes de su consagración obispal (Cf. «Introducción» a la ed. de Dales/Gieben, Oxford, 1982). Contemporánea del Comentario a los Analíticos y de sus obras científicas de madurez, ofrece también la consolidación de otros trabajos teológicos anteriores y conjuga ideas ya expuestas en el Comentario a la Física, en el De luce y De operationibus solis. Plantea allí por única vez en su obra, de modo sistemático, el tema del objeto propio de la Teología, retomando la idea del- «Christus totus» de que hablaron los SSPP y sobre todo Agustín. Apunto aquí solamente que en esta línea propone una explicación comprehensiva del tema de los motivos de la encarnación del Verbo (cf. J. Mc Evoy, «The absolute predestination fo Christ in the theology of Robert Grosseteste», Sapientae doctrina. Melanges de théologie et de llittérature médièvale offerts a Dom. Hildebrand Bascour OSB, Rech. Théol. Anc, Méd. (esp. 21, 1979: 52-62). M. Scoto resume y retoma estas ideas en I Sent., prol. Q. 8, art. 5. Como señala Emile Mersch, lo que asombra a Grosseteste y le hace reflexionar en especial, es la diversidad de aspectos que contribuyen a formar un único objeto (Cf. «L'objet de la théologie et le Christus totus», Rech. Scienc. Relig., 26, 1936: 129-157). Indudablemente algunas dificultades metodológicas (y no sólo el apego a la tradición) obstaculizaron a Grosseteste la concreción de un sistema complexivo de las cuestiones teóricas de la teología, a lo cual debe sumarse el hecho de que él mismo, pese a su suspicacia sobre la incorporación a la teología de conceptos filosóficos griegos, use terminología aristotélica en algunas cuestiones difíciles (cf. K. M. Purday, «The diffinicio Eucharistie of Robert Grosseteste», Journal theol. studies 27, 1876: 381-390). Lo cual no le impide ceñirse a fuentes tradicionales en el caso de temas de más peso bíblico (cf. J. Mc Evoy, «The text and sources of the Treatise De Decem Mandatis of Robert Grosseteste», Rech. théol. anc. méd. 58, 1991: 206-212). Pareciera entonces que hay en él un cierto pragmatismo metodológico, en el sentido de que va escogiendo los modos más adecuados de dilucidar problemas puntuales de su interés. 
continuadores $^{3}$, sistematiza todo este tema alrededor de la categoría de credibilia (lo creíble). El primer versículo del Génesis es el primer «creible» y el más importante. En este trabajo veremos las consecuencias filosóficas derivadas de esta conceptualización. Pero previamente analizaremos más detalladamente esta categoría, a fin de hacer más clara la comprensión del tema que específicamente nos ocupa.

Grosseteste comienza preguntándose por el objeto de la teología, y responde que es el Christus integer (I, I, 1, p. 49). Pero este objeto (o subjectus como él lo denomina) no es evidente por sí ni resultado de una indagación científica (I, $\amalg, 1$, p. 50), ni podría ser captado intelectualmente sin ser primero creido. Esto se debe a que el objeto de la teología (y sus derivados, añadimos) no se comprende en ninguna de las divisiones del ente que estudia la filosofía. En otros términos, no es por sí objeto específico de ningún método científico. Recordemos que para la filosofía (ciencia estricta del s. XIII) Dios en cuanto primer motor o causa del mundo es objeto propio de la metafísica o teología natural, siguiendo las afirmaciones del L. IV de la Metaphysica aristotélica. Pero el Cristo íntegro y todo lo que en Él se resume (incluyendo la revelación de la creación) no es Dios en ese sentido filosófico. Esta primera intuición sobre la inconmensurabilidad del lenguaje filosófico y el teológico lleva a la postulación de los credibilia.

No da Grosseteste una definición general del concepto, que parece conexo simplemente a su significado vulgar. Lo más importante es la función que asigna a esta categoría. Podemos preguntarnos, en primer lugar, qué es concretamente «creíble». Aunque no se explicita, no puede dudarse que aquí el Lincolniense se refiere primera y propiamente a la proposición (enunciado lingüístico) descriptiva, y susceptible por tanto de ser calificada como verdadera o falsa. Si una proposición es declarada «creíble» más bien que «cognoscible» (en el sentido de «comprobable» o «demostrable») entonces puede ser principio de un acto de fe sin introducir contradicción en el intelecto. De allí que las proposiciones propias de la teología sean más bien «creíbles» (credibilia) que «demostrables» (scibilia).

¿Cuándo y por qué una proposición es creíble? Las dos causas o fundamentos de credibilidad aceptados por Grosseteste son la verosimilitud y la autoridad (I, II, 2, p. 51). Hay, pues, una credibilidad fundada intrínsecamente y una credibilidad de fundamento extrínseco. La verosimilitud es la apariencia de verdad que puede exhibir una cosa: en este caso la proposición descriptiva de un estado del universo ${ }^{4}$.

Naturalmente esta verosimilitud tiene grados, que están dados por la mayor o menor aproximación a la evidencia. Pero esta credibilidad no interesa en teología, donde la materia propia de la fe es creíble, en cuanto tal, sólo por la autoridad revelante. De allí que Grosseteste afirme que la credibilidad de verosimilitud es accidental en teología. Sin embargo, para el deslinde entre ésta y la filosofía jugará un papel capital, como veremos enseguida.

Resta, pues, que la credibilidad teológica tiene fundamento extrínseco: la autoridad divina, que torna igualmente creíbles todas las materias de fe, aunque algunas sean más fácilmente «imaginables» (comprensibles) que otras (I, II, 2, p. 51). De estas cosas creíbles, las más fácilmente imaginables o comprensibles son aquellas que se refieren a los objetos naturales como

3 Cf. Richard Dales, «The influence of Grosseteste's Hexaemeron on the Sentences Commentaries of Richard Fischacre OP and Richard Rufus of Cornwal OFM», Viator, Med. and Renais. Studies 2, 1971: 271-300. Uno de los aspectos influidos es precisamente el tratamiento del tema de la no eternidad del mundo.

4 Para Grosseteste, como para otros contemporáneos suyos, la verosimilitud es una característica común a la ciencia, la fe y la opinión, pero estos tres órdenes de conocimiento se distinguen —entre otras cosas- por la diferente manera de certificarla. Mientras que la scientia debe lograr la certeza objetiva, las otras dos sólo proporcionan certeza subjetiva y por tanto en definitiva deben usar el recurso a la autoridad. De allí que incluso el conocimiento científico vaya a resultar jerarquizado según el mayor o menor grado de certeza que proporcione (cf. Juan F. Tudela van Breugel, «La jerarquía de las ciencias según Roberto Grosseteste», Boletín del Instituto Riva Agüero, 12 , 11982-83: 375-390). 
el cielo y la tierra. Por eso la Escritura se refiere a ellos, a fin de proponerlos a todo el género humano de la manera más sencilla y como presupuestos de las otras cosas que se revelarán. Es así que si bien las cosas, o el mundo, en cuanto ahora lo conocemos, es objeto del sentido y de las demostraciones científicas, en cuanto a su origen (la creación) es materia de fe (I, II, 3 , p. 51). Concretamente la proposición creíble en virtud de la revelación divina es: «la creación temporal y sucesiva de las cosas corporales y visibles del cielo y la tierra y sus ornatos» (I, III, 1, p. 52). Y a continuación precisa que éste es el sentido literal de lo revelado, en el cual no figura de modo expreso la creación de los ángeles y en general del mundo inteligible, pues la Escritura se refiere en primer término al mundo sensible. Con esta restricción, Grosseteste elimina de la materia «creíble» toda la interpretación alegórica tan cara a la tradición, y en este punto hallará continuadores conspicuos ${ }^{5}$. El aparente empobrecimiento exegético tiene una doble compensación: el primer sentido, o sea, el literal, resulta así propiamente descriptivo, en términos inmediatos y una vez explicitado mediante el recurso racional (la ciencia) podrá convertirse de credibilia en scibilia ${ }^{6}$. Claro que este paso no es fácil ni evidente, y de hecho sin esa ayuda inestimable de la revelación no se hubiera podido dar.

La razón de que el sentido literal sea inmediatamente descriptivo del mundo real es que expresa las ideas o arquetipos eternos en la mente divina (I, III, 2, p. 52) ${ }^{7}$. Y naturalmente esta sabiduría divina será «la luz que ilumina a todo hombre que viene a este mundo» $(J u 1,9)$. Es decir, hay en definitiva no sólo continuidad sino incluso unidad esencial en los contenidos creíbles y cognoscibles racional o sensiblemente, pero para llegar a captarla es necesario superar la barrera de la inconmensurabilidad de sus respectivas vías de acceso y expresión. Esta es la tarea de la categoría conceptual de los credibilia, que se constituye concretamente como un puente teórico entre las proposiciones que son propiamente objeto de la filosofía y aquellas que lo son de la teología.

\section{LA CREATIO EX NIHILO}

El primero de los credibilia es el postulado enunciado en los versículos iniciales del Génesis. Es justamente un punto crítico en que los dogmas fideístas entran en confronte con los resultados establecidos de la más alta especulación humana natural. Cada saber puede recla-

5 Esta eliminación no le impide aceptar algunas ideas conexas ya bien elaboradas por los SSPP, como la verdad y la inerrancia del texto mosaico, defendidas con buenos argumentos filosófico-racionales por Agustín (por ejemplo De doctrina christiana II, II, 42, PL 34, 65) y Basilio (Hexaemeron, I, I, 1 ss). Rufus continúa estas ideas en su Comm. in Sent. II, d. 12 (cf. Dales-Gieben, ed. cit. p. 52, 2 nota 6) y también Scoto en el Pról. pars 3, Q. 2 de la Ordinatio. V. el comentario que acompaña la edición de este fragmento por G. B. Phelan, «An uneditet text of Robert Grosseteste on the subject-matter of Theology», Rev. néosc. phil. 363, 1934: 176-179.

6 Dado que para Grosseteste el orden de la ciencia está en relación con el orden del ser (éste fundamenta a aquél y no a la inversa), hay scibilia acerca de los cuales sólo podemos tener un conocimiento imperfecto, y sin embargo constituyen el objeto de una ciencia más alta, como es el caso de la teología. Pero esta defectibilidad de nuestro conocimiento racional analítico (el de las ciencias proprie y magis propie o sea, la física y la matemática respectivamente) es suplida por el conocimiento iluminativo. Puede coincidirse con R. J. Palma en que las deficiencias de esta epistemología se deben en buena medida al dualismo ontognoseológico del Lincolniense, cuyas dicotomías (por ejemplo mutable/inmutable, inteligible/sensible, etc.) impiden cualquier intento de unificación del método filosófico (cf. «Grosseteste's ordering of scientia», New Scholasticism 50, n. 4, 1976: 447-463).

7 Esto es así porque el Lincolniense admite el conocimiento por iluminación y por tanto las verdades particulares descritas en un texto (en nuestro caso las que corresponden al sentido literal) se relacionan con la Verdad suprema en términos de iluminación subjetiva y objetiva por la luz suprema. Este es el planteo general de su gnoseología conforme lo expone en De veritate. Como ha observado J. Mc Evoy; esta obra y la teoría en ella contenida no se oponen a la visión del problema que presenta al comentar los Analíticos Posteriores porque, aunque admite la validez del esquema abstractivista aristotélico, lo declara insuficiente para conducir a la Verdad suprema (cf. «La connaissance intellectuelle selon Robert Grossetete», Rev. philos. Louvain 75, n. 25, 1977: 5-48). 
mar para sí, con legitimidad, ese objeto, pero las soluciones - así como las vías de accesono necesariamente han de coincidir, y de hecho no han coincidido en la historia del pensamiento humano. Sin embargo, todo creyente tiene el convencimiento de que la contradicción objetiva es imposible. La cuestión es cómo explicitar las vías de disolución de posibles y aparentes contradicciones. Esta preocupación fue común a los sabios creyentes de los tres grandes monoteísmos occidentales. La solución que propone Grosseteste, además de ser indudablemente ingeniosa, por cuanto evita la alternativa fideísmo-racionalismo, que dio tanto trabajo a Averrores, Maimónides y Tomás de Aquino, es interesante desde el punto de vista de una posible relectura filosófica del pensamiento mítico, que permite superar el apriorismo con que suele eliminárselo del ámbito del lenguaje estrictamente significativo (es decir, descriptivo). Diríamos que Grosseteste, mediante estas consideraciones, amplía el espectro de la descriptividad lingüística y en ese sentido podríamos considerarlo un partidario de la «racionalidad amplia» que hoy se postula desde ámbitos muy distintos. En los próximos puntos intentaré justificar esta interpretación.

\section{La autoridad escriturística sobre la creatio ex nihilo}

Ya indiqué que lo «creíble» en sentido teológico tiene un fundamento específico que es la autoridad divina, expresada en el sentido literal del texto revelado. En relación a este tema, la Escritura enuncia tres afirmaciones: $1^{a} \mathrm{El}$ mundo fue hecho de la nada preexistente (noción estricta de creación, donde «preexistencia» obviamente no debe entenderse en sentido temporal sino subjetivo, es decir, de la nada subjetiva, o material, o sustantiva); $2^{\mathrm{a}}$ Fue creado en el tiempo (es decir, tiene una duración anterior finita) y $3^{\mathrm{a}}$ Fue creado sucesivamente.

Estas tres proposiciones son al menos distintas de las que enseñan los filósofos, especialmente los dos grandes maestros griegos, Platón y Aristóteles. Con respecto a la primera, hay simple diferencia, ya que ellos no conocieron la noción de «creación» y por tanto en este sentido sus afirmaciones son inconmensurables con las judeo-cristianas. La segunda, en cambio, introduce una auténtica contradicción, sea con Aristóteles, quien enseña que el mundo no tuvo principio, sea con Platón, que indirectamente sostiene lo mismo al admitir una especie de temporalidad circular infinita (I, VIII, 1, p. 58). En cuanto a la tercera, se le oponen todas las concepciones a-temporalistas del desarrollo del mundo, entre las cuales están en primer término las concepciones emanatistas, cuyo concepto de «temporalidad» —-si así puede decirse- - difiere del tiempo propio y real sugerido en le Génesis.

De todos los filósofos que pudieron disentir o diferir con la revelación, el más importante es Aristóteles, porque su sistema metafísico y cosmológico tenía un peso incomparablemente mayor que los otros, en forma global y en cuanto explicación total y sistemática del universo. De allí que todas las controversias surgidas entre los creyentes de las tres religiones que comparten la creencia en el Génesis, lo hayan tenido por interlocutor principal y casi exclusivo. Grosseteste se ocupó del tema, en forma cuidadosa, en dos ocasiones: en el Comentario a la Physica y en el Hexaemeron. En esta última obra enuncia definitivamente los criterios teológicos a tener en cuenta con respecto a Aristóteles. En la otra, hace un análisis del sentido de las afirmaciones del Estagirita. Es decir, en el Hexaemeron contrapone la «razón» aristotélica a la «fe» en los credibilia en virtud de la autoridad. En cambio, en el Commentarius se preocupa por dilucidar el carácter exacto de la contradictoriedad de las dos proposiciones en juego y por ende, su metodología responde más bien al objetivo de fundamentar filosóficamente la credibilidad intrínseca o verosimilitud de la proposición creíble. Si sólo hubiésemos contado con la apelación a la credibilidad extrínseca, el aporte de Grosseteste no hubiera sido muy distinto al de toda la tradición patrística que en cierto modo asumió y resumió decantadamente en sus obras teológicas. Y si sólo hubiésemos tenido el Commentarius, no hubiéramos podido reconstruir la función de los credibilia como puentes entre la razón y la fe. 
La primera afirmación de Grosseteste al respecto, tanto en el Hexaemeron como en el Commentarius $^{8}$ es hacerse cargo de la contradicción: según la Biblia, el tiempo anterior al presente es finito, según Aristóteles es infinito. Finito e infinito son contradictorios, luego ambos no pueden ser verdaderos. Si creemos en la Biblia y ella es para nosotros verdadera, Aristóteles necesariamente está equivocado. Solución sencilla al problema, estaba lejos de ser aceptada pacíficamente. El mismo Grosseteste nos indica que frente a los textos aristotélicos había al menos dos posiciones tomadas y que él mismo analiza. Una es interpretar «cristianamente» a Aristóteles, sosteniendo que en realidad no enseñó positivamente la infinitud temporal del mundo. El Lincolniense no tiene pelos en la lengua para criticarlos:

Sin embargo hay ciertos modernos, vanos filosofantes, y sobre todo algunos dementes ignorantes, que afirman que Aristóteles no quiso decir que el mundo careciera de inicio temporal, sino que lo entendió en sentido católico y admitió un inicio del tiempo y del mundo. Contra ellos está el texto mismo de Aristóteles y los argumentos aducidos para su conclusión, y la última conclusión de su libro, que quiere probar el primer motor por la perpetuidad del movimiento. Todos los expositores de este paso de Aristóteles, tanto griegos como árabes, hablan aquí de la perpetuidad del movimiento, el tiempo y el mundo, es decir, de su duración infinita en ambos sentios y así lo exponen concordantemente.

(I, VIII, 2, p.58-59)

Y luego de explicar las interpretaciones correctas de Aristóteles, Platón y otros filósofos, concluye que la revelación mosaica es inédita en el mundo del pensamiento y este hecho debe reconocerse:

Por todo lo dicho y mucho más que podría añadirse si no fuera excesivo, resulta evidente que muchos otros filósofos, como Aristóteles, aseveraron que el mundo carece de principio temporal; a todos los cuales golpea y refuta Moisés diciendo 'En el principio'. Adujimos esto contra algunos modernos, que intentan hacer de un Aristóteles herético un católico, contra el mismo Aristóteles y sus propios expositores, juntamente con los sacros, creyendo con admirable ceguera y presunción que entienden e interpretan mejor a Aristóteles a partir de textos latinos corruptos, que los gentiles y católicos que conocieron su texto incorrupto en el original griego. Y así no se disuaden de hacer católico a Aristóteles, consumiendo inútilmente su tiempo y las fuerzas mentales, y queriendo hacer católico a Aristóteles, ellos mismos se vuelven herejes.

(I, VIII, 4, p. 60-61)

En las fuertes invectivas del párrafo adivinamos la agria controversia aristotélica de mediados del s. XIII y las suspicacias y rencores que los llamados «averroistas latinos», en su mayoría profesores de Artes, despertaban en los teólogos 9 . Pero Grosseteste no era hombre de quedarse en ello. Y así, luego del sed de hiis hactenus pasa al tratamiento analítico de la cuestión.

Una segunda posición frente a la teoría aristotélica era la tradicional patrística y monacal: oponer a la afirmación del Estagirita el propio dogma. Esta solución satisface al creyente, pero sólo medianamente al filósofo. Y esto ya lo sabían los primeros Padres que intentaron una demostración positiva de la verdad bíblica. Grosseteste mismo se refiere a ello en su Commentarius. ¿Por qué no basta la oposición dogmática? Creo que —al menos en el pensamiento de

8 Citamos por la edición de Richard C. Dales, Roberti Grosseteste Commentarius in VIII LIbros Physicorum Aristotelis, Boulder, University of Colorado Press, 1963.

9 Cf. este punto en el estudio clásico de E. Gilson, «Les sources gréco-arabes de l'agustinisme avicennisant», Arch. d'hist. doc, et lit. du Moyen Âge 4, 1929-30: p. 92 ss. sobre los antiaristotélicos que se inclinan por la síntesis aviceniano-cristiana de Gundisalvo y sus seguidores. Y especialmente para las doctrinas de los «teólogos» suspectantes cf. Pierre Feret, La Faculté de Théologie de Paris et ses docteurs les plus célèbres, T. I, Moyen Âge, Paris, Ricard et Fils, 1894, especialmente «Los sorbonistas» (p. 203 ss) y «Los franciscanos» (p. 275 ss). 
Grosseteste- - la razón ha de buscarse en la inconmensurabilidad de los lenguajes: las proposiciones de fe son verdaderas en sentido absoluto, pero el contexto de su enunciación es la credibilidad extrínseca. No es legítimo entonces usarlas sin más como verdades cuya credibilidad debe ser al menos intrínseca, como condición absoluta de la verdad científica. Por lo tanto, por sí mismas no pertenecen a la filosofía. Pero para quien no ha renunciado a la razón natural, sólo la credibilidad intrínseca puede ser un motivo autónomo que justifique una afirmación dogmática ulterior. Sobre este sencillo principio se constituyó después toda la apologética o teología fundamental, pero el camino hacia la comprensión de la naturaleza especial de estas proposiciones «fronterizas» fue largo y tortuoso.

Grosseteste resume al final de su Tractatus de finitate motus et temporis un argumento atribuido a Ricardo de San Victor ${ }^{10}$

\begin{abstract}
Arguye el maestro Ricardo de San Víctor que el tiempo no es infinito con respecto al pasado. Éste, es decir, todo el tiempo hasta ahora, es pretérito, pero este pretérito alguna vez fue presente. Luego ningún tiempo es pretérito sin que primero haya sido presente. Por lo tanto el presente existió antes que algo fuera pretérito, y así el pasado es finito.

Del mismo modo puede razonarse con respecto al futuro, aunque el mismo maestro no retrueca así. Se prueba también que algún tiempo será finito con respecto al futuro de este modo: todas las cosas han sido hechas por causa del hombre, el movimiento del cielo para que la generación y la corrupción sean continuas, en cuanto estos cambios son para el hombre, en su necesidad o ayuda. Luego, como el hombre no produce estos cambios, no habría causa por la cual el cielo se moviera; por tanto el cielo y el tiempo se detendrán cuando cese la generación del hombre.
\end{abstract}

(Com. in Octo Phys. VIII, ed. Dales, p. 154-155).

Lo que no place del todo a Grosseteste en estos argumentos, aunque los acepte reverentemente, es que en el fondo son puramente verbales, y en ese sentido, en cuanto dependen de la definición de las palabras, son metodológicamente susceptibles de los mismos reproches que los argumentos contrarios aristotélicos, también verbales. Si hemos de dar un argumento definitivo en sede teológica, deberá por fuerza ser a su vez teológico. Y ese es el argumento final: el universo tiene en el hombre la razón de su existencia y en cuanto la vida de la humanidad es limitada también lo será la del mundo. Es claro que este argumento supone a su vez otro dogma, que es el fin de los tiempos humanos, la parusía. Esta circularidad es inevitable, ya que -él mismo la asumió al comienzo - las verdades de fe constituyen un universo de discurso diferente del empírico y/o científico. Esto mismo las diferencia claramente de las verdades propiamente filosóficas.

A las dos actitudes mencionadas Grosseteste añade una tercera, que es la propia, consistente en mostrar racionalmente de dónde ha provenido el error filosófico de explicar los fundamentos racionales de la credibilidad extrínseca. Así se da el paso a la credibilidad intrínseca o verosimilitud.

\title{
II. La verosimilitud de la creatio ex nihilo
}

Hay una cuestión que han discutido Muckle ${ }^{11}$ y Dales ${ }^{12}$ : si Grosseteste conocía la Physica aristotélica al tiempo de escribir el Hexaemeron. Esto estaría relacionado con sus labores de tra-

10 Dales indica que este argumento no pudo ser hallado en los textos del Victorino, según Opera Omnia de PL 196 (Dales, ed. Comm. cit. p.154, nota 1).

11 «Robert Grosseteste's use of greek source in this Hexaemeron», Medievalia et Humanistica 3, $1945:$ 33-

48 y «The Hexaemeron of Robert Grosseteste», Medieval Studies 6, 1944, 151-174.

12 «A note on Robert Grosseteste's Hexaemeron», Medievalia et Humanistica 115, 1963: 69-73. 
ducción y su pretensión de disponer de textos más confiables que los latinos «corruptos» a que hace referencia. Dales se inclina a pensar que en realidad conoció las teorías de los Libros VII y VIII a través de traducciones latinas y que sería el ignoto opositor de Guillermo de Conches. Sin embargo, el mismo Dales, prologando su edición del Hexaemeron (junto con Gieben, un gran conocedor de Grosseteste) reconoce que éste logró dominar el griego en la época de su madurez intelectual ${ }^{13}$. La cuestión es relevante desde el punto de vista de la historia interna de la controversia antiaristotélica, porque aclararía, al menos en parte, la cuidadosa explicación semántica y gramatical exhibida en las dos obras que analizamos, y que despejó definitivamente la vía de soluciones al estilo de la atribuida a Ricardo Victorino, dando lugar a respuestas filosóficamente más interesantes y entre sí distintas, como las de Santo Tomás o Scoto.

Grosseteste despliega su arsenal analítico en dos pasos: en primer lugar muestra de dónde proviene la errónea afirmación de la eternidad del tiempo, en segundo, fundamenta racionalmente la credibilidad intrínseca de la creatio ex nihilo.

A. El error de los antiguos filósofos. Grosseteste da dos explicaciones, que repite en ambas obras mencionadas. Una es la falsa imaginación; otra, una cuestión de lenguaje. Las analizaremos brevemente.

a. La falsa imaginación. Los textos del Commentarius y el Hexaemeron al respecto son rigurosamente paralelos:

El afecto de los filósofos estaba más ligado a las cosas transitorias que a las eternas y su aprehensión, obtenida en las imágenes de lo mudable, no podía alcanzar la simplicidad de la eternidad. Por eso les fue necesario imaginar un tiempo anterior a todo tiempo, y así, antes de cualquier movimiento imaginaron otro movimiento, del mismo modo como se imagina un espacio fuera del cielo, y fuera de ese espacio otro, y otro, al infinito. Esta falsa imaginación de la infinitud del tiempo con respecto al pasado indujo por necesidad a la falsa imaginación de la perpetuidad del movimiento y del mundo, y de las creaturas coetáneas a Dios.

(Comm. in Octo Phys., VIII, ed. Dales, p. 47)

Debe saberse que aquello que llevó a los antiguos a admitir un mundo sin inicio, principalmente fue la falsa imaginación que los hizo creer que hay un tiempo anterior a todo tiempo, al modo como lo imagina la fantasía, y que hay un lugar fuera de todo lugar y un espacio fuera de todo otro, y así al infinito. Por tanto la corrección de su error sólo puede lograrse eliminando de la mente el apego a las cosas temporales, para que la mirada del intelecto, inmune ya a las imágenes, pueda trascender el tiempo y captar la eternidad absoluta, donde no hay ninguna extensión según lo anterior y lo posterior, y de la cual procede todo tiempo, tanto anterior como posterior.

(Hexaemeron, I, VIII, 5, ed. Dales-Gieben, p. 61)

Ésta es la generalización explicativa de los errores particulares de las teoría de Platón, Aristóteles y sus continuadores respectivos, cuyo análisis pormenorizado podemos omitir, dado que aquí nos ocupa el planteo metodológico. La afirmación principal es siempre la misma: en cualquiera de los sentidos en que se entienda la infinitud del movimiento postulada por Aristóteles -y cualquier otra teoría de resultado equivalente- es falso y herético (Comm. VIII, $\mathrm{p}$. 146). Esta es una doble afirmación: la infinitud del movimiento - y en consecuencia del tiempo- - es un error tanto contra la razón como contra la fe. Hallamos una formulación semejante en otros contemporáneos, como Buenaventura y en general la escuela franciscana de la primera y segunda generaciones ${ }^{14}$. Pero el Lincolniense ofrece una variante: no dice que la

13 Cf. Richard C. Dales-Servus Gieben, «The Proemium to Robert Grosseteste's Hexaemeron», Speculum 43, n. 3, 1968: 451-461.

14 Es decir, excluyo de esta semejanza la formulación de Scoto y las posteriores, porque creo que si bien los resultados apuntan en el mismo sentido, la metodología filosófica ha variado significativamente, plegándose a las exigencias aristotélicas acerca de la investigación de los entes naturales, cosa que todavía no se da tan sistemáticamente en Buenaventura, Juan de la Rochelle y Mateo de Aquasparta. 
eternidad del movimiento y el tiempo sean metafísicamente imposibles, sino que los argumentos con los cuales han intentado probarse no son correctos. Algo semejante dirá Tomás de Aquino en su comentario a la Física ${ }^{15}$ y por la misma causa: el yerro del argumento proviene de haber intentado imaginar en lugar de entender. Es decir, se ha querido dar un contenido descriptivo al lenguaje usado, semejante al habitualmente descriptivo de la realidad empírica, sin entender que el planteo la trasciende. Sin embargo, hay un punto en que la intuición de los antiguos fue certera, a juicio de Grosseteste: los griegos llegaron a probar que toda duración finita debe fundarse de algún modo en una duración infinita de la cual procede. Pero como no entendieron bien el concepto de eternidad (duración simple y simultánea, distinta del tiempo sucesivo) extrapolaron lo que conocían, la temporalidad, considerándola infinita.

Debe destacarse que cuando Grosseteste dice que los antiguos cayeron «necesariamente» en este error, lo dice en descargo de ellos, sin quitar valor científico a sus argumentos. En ese sentido es muy claro en su Commentarius (VIII, p.146): con los medios teóricos que poseían no podían hacer otra cosa, ya que el conocimiento de la eternidad simple y perfecta no proviene de la experiencia ni de la inducción científica. Por eso sólo un filósofo cristiano, que hubiera adquirido por revelación ese conocimiento, podría purgar su entendimiento de estas nociones incompletas más que falsas, y solucionar el problema del fundamento absoluto de la temporalidad. Este resultado a primera vista no difiere de todos los que la tradición católica ha elaborado al respecto. Sin embargo hay un punto en que el pensamiento del s. XIII intenta una inflexión diríamos «racionalista», ausente, al menos con esos efectos, en la tradición patrística y monástica. En primer lugar, deja en claro que la referencia al plano teológico es indirecta y no directa, es decir, el contenido revelado no se asume sin el previo recaudo de una reformulación contextual. Así, los ámbitos de discurso permanecen distintos y cada uno opera según sus categorías propias. En segundo lugar, la corrección o el añadido proveniente de este nuevo dato no altera el discurso científico en sí, y no podría hacerlo porque previamente se han distinguido con cuidado los ámbitos lingüísticos en que se expresa, así como el tipo de «credibilidad» que funciona en cada ámbito, aun para un enunciado materialmente (semánticamente) idéntico. Es obvio que hoy esta respuesta nos parece insuficiente, pero porque hoy distinguimos también semánticamente los universos discursivos de filosofía y teología, y nos hemos acostumbrado tanto a hacerlo que casi nos pasa inadvertido el esfuerzo intelectual que ha costado.

b. La cuestión del lenguaje. Grosseteste fue uno de los pocos que analizó más sistemáticamente la cuestión linguiística implicada en las discusiones metafísicas, concretamente en este tema de la infinitud del tiempo. El análisis semántico que ofrece su Tractatus de finitate motus et tempori ${ }^{16}$ es un modelo en su época. Allí resume el argumento aristotélico del modo siguiente: cuando algo que está en potencia no pasa al acto, es por falta de alguna condición, sea de parte del agente o de parte del paciente. Entonces, para que se dé esa condición y se produzca el primer movimiento, es preciso adquirirla, lo que se produce necesariamente por un movimiento. Por eso siempre hay movimiento antes del movimiento. Pero de acuerdo a este

15 Cf. Lib. VIII, Lec. XVIII y ss. He analizado este tema en «Los Comentarios de Santo Tomás y de Roberto Grosseteste a la Física de Aristóteles», Sapientia 25, 1970, p. 273 ss. Tampoco Tomás está de acuerdo con la interpretación «piadosa» de Aristóteles: su argumentación es errónea, pero no puede derivarse de sus conclusiones más de lo que los textos en sí mismos autorizan; de allí que niegue los resultados fuertes de Averroes, que a su juicio son extralimitaciones exegéticas.

16 Este tratado, que constituye una unidad independiente, fue editado por Dales a continuación del Commentarius, p. 144 ss. Sus características distintivas, en relación al texto anterior, son por una parte la exposición más completa de la interpretación de Averroes, y por otra los notables paralelos con textos del Hexaemeron que el mismo Dales se encarga de señalar en su edición. Digo que es un modelo, porque es uno de los primeros y más tempranos acercamientos latinos a los textos averroístas (c. 1230) es decir, al mismo tiempo en que eran conocidas en la latinidad las traducciones completas del corpus averroísta. 
argumento, también podría probarse lo contrario: que no hubo movimiento antes del movimiento, o que alguna vez hubo un reposo sin movimiento intermedio (Comm. VII, p. 148-149). Es decir, esta prueba se completa con el postulado de existencia, que sería en este caso simple admisión de la evidencia empírica. Prescindiendo de los aspectos metafísicos del argumento, Grosseteste lo enfoca desde el punto de vista lógico-semántico.

Hay un sentido en que la argumentación del Estagirita es verdadera, y otro en el cual es falsa. Es falsa si «antes» y «después» se toman en ambos casos con significación temporal; pero es verdadera si el «antes» se toma en sentido no temporal, refiriéndolo a la eternidad. Asimismo, el argumento es falso si «potencia» se entiende como potencia material, porque antes de la creación no había materia en la cual todo estuviera en potencia, ya que la materia también fue creada al comienzo del tiempo (cf. Libro I del Comm.) Pero es verdadero si «potencia» significa la potencia activa de la causa eficiente.

La refutación a la pretensión absoluta de la conclusión aristotélica se basa en la noción de eternidad. Pero en sentido aún más estricto podría decirse que el núcleo de la crítica es que «antes» $\mathrm{y}$ «después» no deben ser entendidos en sentido temporal (aun cuando no quede claro en qué sentido deban entenderse) porque se produce una incorrección semántica ${ }^{17}$.

El mismo principio preside la crítica al que Grosseteste llama tercer argumento aristotélico, tomado de la naturaleza del instante (Bk $251 \mathrm{~b} 14 \mathrm{ss}$ ): instante es continuación de todo pasado y de todo futuro. Luego no hubo instante antes de que hubiera tiempo, ni habría instante después que dejara de existir el tiempo. Y así el tiempo existió sin comienzo y existirá $\sin$ fin. Pero no hay tiempo sin movimiento; luego el movimiento es perpetuo. La respuesta del Commentarius (VIII, p. 151) es equivalente a la del Hexaemeron:

Lo que dicen: que todo cambio es precedido por otro cambio y que todo instante es medio entre el pasado y el futuro, es falso. Pues el cambio del no-ser absoluto al ser no puede estar precedido por otro cambio, ni el instante que es comienzo del tiempo es continuación del pasado con el futuro, sino sólo comienzo del futuro.

(I, VIII, 6, p. 62)

Grosseteste advirtió bien que el problema se deshacía exhibiendo el carácter estipulativo de las definiciones aristotélicas. Negando la validez de la definición se niega automáticamente la consecuencia. Por cierto, Grosseteste no está en la línea de la analítica ligüística, ni sostiene el carácter estipulativo de toda definición no empírica. Pero sí niega validez a la generalización absoluta de una proposición empírica. Así, podemos conceder, con Aristóteles, que empíricamente (según nuestra experiencia actual) el instante es la continuación del pasado con el futuro. Pero de allí no se sigue que esa caracterización descriptiva del instante empírico sea a la vez una definición esencial y absoluta del concepto, de modo que puedan extraerse de ella conclusiones empíricamente significativas (la infinitud temporal). Este punto de vista, que Grosseteste ha aplicado varias veces en su Commentarius, fue una vía filosófica potencialmente rica, aunque lamentablemente poco aprovechada después.

B. La verosimilitud de la creatio ex nihilo. Este punto es complemento necesario de la elaboración anterior. No basta, en efecto, con criticar la postura aristotélica y por extensión todos los infinitismos temporales, si no puede demostrarse al menos la consistencia intrínseca de una teoría alternativa. Es obvio que el primer paso ya está dado: si la proposición contradictoria no es necesariamente verdadera, resta que sea, a lo más, probable, y por tanto al menos igual grado de probabilidad tendrá la otra contradictoria.

17 La razón es que se daría una especie de círculo vicioso: si se presupone que la denominación connota un carácter esencial (en este caso la temporalidad de «antes» y «después») y se aplica el predicado a todo lo mentado por ese término, entonces en realidad no se prueba tal carácter, porque el presupuesto no está probado. En la disputa sobre la infinitud temporal precisamente lo que se cuestiona es lo que el argumento infinitista supone. 
Pero además es necesario patentizar la verosimilitud intrínseca, que ha de ser algo más que mera ausencia de contradicción intrínseca. En otros términos, no todo lo no-contradictorio es verosímil en el sentido exigido por la categoría de credibilia. No puede ser sólo posibilidad intrínseca absoluta, sino que debe ser, por así decirlo, una posibilidad «fuerte». Para asegurar este tipo de verosimilitud no basta la consistencia de una argumentación, sino que debe tener algún correlato ontológico, al menos posible. Esto es lo que Grosseteste intenta al referir estas nociones al concepto de principio y primera causa. «Principio» es una categoría básica para este cometido, ya que no es meramente analítica, pero tampoco es puramente empírica. En la caracterización que nos da Grosseteste (Hexaemeron $\mathrm{I}, \mathrm{IX}, 1$, p. 63) hay un intento de síntesis entre lo analítico y lo empírico, con un uso un tanto errático pero no equívoco de la analogía: principio es aquello que precede a algo en algún sentido. Podemos conceder sin más su analiticidad y por ende su no inmediata descriptividad. Pero cuando aplicamos esta definición formal a los diversos géneros, obtenemos proposiciones con sentido descriptivo: principio temporal, causal, etc. Esta estrategia ya había sido enunciada en el Commentarius, a propósito de las definiciones formales (L. II, p.31 ss). Allí sentó el principio de que las definiciones formales (analíticas, diríamos) son autoevidentes y no demostrables. Para dotarlas de sentido descriptivo deben combinarse con proposiciones empíricas o con postulados de existencia. Esto fue una observación sagaz, bien recogida por $\mathrm{Scoto}^{18}$. Esta idea está implícita en este tema, aunque sin un desarrollo filosófico.

Estas proposiciones «mixtas» no son autoevidentes y tampoco resulta fácil establecer su comprobabilidad empírica o lógica. Pero responden a las exigencias gnoseológicas de la verosimilitud intrínseca de los credibilia, y con eso basta. En cierto sentido funcionan al modo de condiciones trascendentales de posibilidad con respecto a las proposiciones cuya verdad queda establecida fuera de toda duda (e. d. las proposiciones de fe). Este es, entonces, un intento de pasaje de lo teológico a lo ontológico evitando el argumento anselmiano, cuyas dificultades sin duda le eran conocidas al Lincolniense. Precisamente su postura, y la que apreciamos luego en Buenaventura y la primera escuela franciscana, es prescindir de la exigencia argumentativa que hace de ciertas proposiciones (por ejemplo «Dios existe») la conclusión realista de un silogismo con premisas formales (analíticas). Reconociendo a la intuición intelectual y a la inmediatez de las categorías ontológicas un lugar que les negará el Aquinate, aparece todo un espectro de posibilidades para la metafísica, que podrá tender variados puentes con las proposiciones de fe. Puentes que deberán renunciar a la apodicticidad del formalismo y el empirismo puros, pero que ganarán en intuiciones ricas y sugerentes. Tal espectro no constituirá nunca, probablemente, un sistema en el sentido anhelado por Tomás y otros maestros de París y fervientemente esperado por la Iglesia como escudo contra los peligros de la creciente herejía. De allí que el s. XIV olvidara estas posibilidades teóricas. Hoy, quizá menos acuciados por preocupaciones de ese tipo, estamos más dispuestos a reasumir y repensar estas antiguas intuiciones, sin esperar de ellas lo que no pueden darnos, pero sin renunciar a lo mucho que de veras ofrecen.

Celina A. Lértora Mendoza E-mail: fepai@clacso.edu.ar

18 Quaest. in Lib. Physicorum, II, Q. 2, donde menciona explícitamente a Grosseteste al dar su propia interpretación sobre proposiciones materiales (de contenido empírico) y formales. 